\title{
Metallopeptidases produced by group B Streptococcus: Influence of proteolytic inhibitors on growth and on interaction with human cell lineages
}

\author{
GEORGIA CRISTINA MONTEIRO TAVOLARO SOARES ${ }^{1}$, BIANCA ALCÂNTARA DA SILVA ${ }^{2}$, \\ MICHELLE HANTHEQUESTE BITTENCOURT DOS SANTOS ${ }^{1}$, ANDRÉIA FERREIRA EDUARDO DA COSTA ${ }^{1}$, \\ ANDRÉ LUIS SOUZA DOS SANTOS ${ }^{2}$, VERÔNICA MORANDI ${ }^{1}$ and PRESCILLA EMY NAGAO ${ }^{1}$ \\ ${ }^{1}$ Departamento de Biologia Celular e Genética, Instituto Biologia Roberto Alcântara Gomes (IBRAG), \\ Universidade do Estado do Rio de Janeiro (UERJ), Rua São Francisco Xavier, 524-PHLC/2 ${ }^{\circ}$ andar, Maracanã, \\ 20550-013 Rio de Janeiro, RJ; ${ }^{2}$ Departamento de Microbiologia Geral, Instituto de Microbiologia Prof. Paulo de Góes \\ (IMPPG), Centro de Ciências da Saúde (CCS), Bloco I-subsolo, Universidade Federal do Rio de Janeiro (UFRJ), \\ Av. Carlos Chagas Filho 373, Cidade Universitária, 21941-902 Rio de Janeiro, RJ, Brazil
}

Received January 31, 2008; Accepted March 27, 2008

\begin{abstract}
Group B Streptococcus (GBS) is a major etiologic agent of neonatal bacterial infections and is the most common cause of sepsis and pneumonia in newborns. Surface and secreted molecules of GBS are often essential virulence factors which are involved in the adherence of the bacteria to host cells or are required to suppress the defense mechanisms of hosts. We analyzed the peptidase profiles of GBS by detection of proteolytic activities on SDS-PAGE containing copolymerized gelatin as substrate. Based on the inhibition by $o$-phenathroline and EGTA, three distinct peptidases of 220, 200 and $180 \mathrm{kDa}$ were identified in the culture medium, besides one major cell-associated proteolytic activity, a 200-kDa metallopeptidase, suggesting that all were zincmetallopeptidases. GBS culture supernatants, rich in metallotype peptidases, also cleaved fibronectin, laminin, type IV collagen, fibrinogen and albumin. Cleavage of the host extracellular matrix by GBS may be a relevant factor in the process of bacterial dissemination and/or invasion. Notably, metallopeptidase inhibitors strongly blocked GBS growth as well as its interaction with human cell lineages. Understanding the contribution of peptidases to the pathogenesis of GBS disease may broaden our perception of how this significant pathogen causes severe infections in newborn infants.
\end{abstract}

Correspondence to: Dr Prescilla Emy Nagao, Departamento de Biologia Celular e Genética, Instituto Biologia Roberto Alcântara Gomes (IBRAG), Universidade do Estado do Rio de Janeiro (UERJ), Rua São Francisco Xavier, 524-PHLC $/ 2^{\circ}$ andar, Maracanã, 20550-013 Rio de Janeiro, RJ, Brazil

E-mail:pnagao@pq.cnpq.br

Key words: group B streptococcus, peptidase, metallopeptidase inhibitors, cellular interaction

\section{Introduction}

Group B Streptococcus (GBS) is a major cause of serious neonatal bacterial infections and is the most common cause of sepsis and pneumonia in newborns (1). GBS is also a significant cause of postpartum endometritis. In addition, data implicate GBS as an increasingly important cause of invasive infections in adults, especially among immuno-compromised individuals (2). GBS has evolved a diverse array of mechanisms to fight the innate immune system, which is important as the first line of defense against bacterial infections in nonimmune hosts (3).

GBS produces a number of extracellular enzymes, several of which interact with the host immune system. These interactions are thought to be important for the host-microorganism interplay and for the development of disease. These enzymes directly or indirectly modulate the activity of defense molecules such as immunoglobulins, complement factors, or other inflammatory mediators, as well as cleave the extracellular matrix components allowing bacteria to disseminate (4).

It is well known that bacterial dissemination from a local site into the systemic circulation is greatly enhanced by bacterial proteolytic enzymes. In this context, studies have correlated the incidence of early-onset neonatal disease as well as premature rupture of membranes with heavy GBS colonization of the vagina, cervix and urine of pregnant women $(5,6)$. The degradation of amniotic collagen fibrils in the presence of GBS may be an important factor contributing to bacterial invasion (7). GBS adherence to and migration through the chorioamniotic membranes have been shown in vitro. Disruption of the collagen fibrils of the amniotic membrane was found in the presence of a GBS isolate from the placenta of a septic neonate, following the premature rupture of membranes (8). Degradation of a collagenous substrate by crude GBS cell lysate was demonstrated by using a synthetic peptide (2-furanacryloyl-Leu-Gly-Pro-Ala), 
which mimics the primary structure of collagen and gelatin (denatured collagen) zymograms, and also by blocking the collagenase proteolytic activity with inhibitors and by anticlostridial collagenase antibody $(9,10)$. Human GBS isolates produce a highly conserved cell wall protein (C5a peptidase; $\sim 120 \mathrm{kDa}$ ) that specifically inactivates C5a. This proteolysis abolishes C5a-induced recruitment of polymorphonuclear neutrophils to the site of infection and binds to fibronectin and promotes invasion of epithelial cells by $\operatorname{GBS}(11,12)$.

The aim of the present study was to characterize cellassociated and secreted peptidases in a clinical isolate of GBS (serotype III isolated from cerebrospinal fluid) and to test its ability for hydrolyzing different protein substrates. In addition, we assessed the effect of metallopeptidase inhibitors on the growth and on the adhesion of GBS to human umbilical vein endothelial and human epithelial pulmonary cells. Finally, we tested the ability of two additional GBS clinical isolates belonging to serotype III and $\mathrm{V}$ in producing peptidases.

\section{Materials and methods}

Chemicals. Reagents used in electrophoresis and buffer components were purchased from Amersham/GE Life Science (São Paulo, SP, Brazil). Brain heart infusion medium (BHI) was obtained from Difco Laboratories (Detroit, MI, USA). Blood agar base (BAB) was purchased from Oxoid (Basingstoke, Hampshire, UK). The proteolytic inhibitors [o-phenanthroline (PHEN), ethylenediaminetetraacetic acid (EDTA), ethylene glycol-bis (ß-aminoethyl ether) (EGTA), trans-epoxysuccinyl L-leucylamido-(4-guanidino) butane (E-64), phenylmethylsulphonyl fluoride (PMSF) and pepstatin A], the proteinaceous substrates [gelatin, bovine serum albumin (BSA), fibronectin, laminin, type IV collagen and fibrinogen], M199 medium, collagenase IV, dithiothreitol (DTT), all the antibiotics and dimethylsulfoxide (DMSO) were obtained from Sigma Chemical Co. (St. Louis, MO, USA). Fetal calf serum (FCS) and DMEM were purchased from Gibco BRL (Gaithersburg, MD, USA). All other reagents were of analytical grade.

Bacterial strains and growth conditions. GBS strain 90356 (serotype III), partially investigated for its adhesive properties (13), was used throughout this study (Table I). The strain obtained from The Culture Collection of the Laboratório de Cocos Patogênicos (Departamento de Microbiologia Médica, Instituto de Microbiologia Prof. Paulo de Góes, Universidade Federal do Rio de Janeiro, Brazil) was identified as group B and serotyped as described previously (14). Two additional clinical isolates were used to demonstrate that the proteolytic activity was a common feature of the GBS species (Table I). Microorganisms were stored after lyophilization and recovered in BHI broth. GBS strains were grown in Erlenmeyer flasks containing $200 \mathrm{ml}$ of two distinct media: BHI and M199 for 16 to $18 \mathrm{~h}$ at $37^{\circ} \mathrm{C}$.

Bacterial cellular extracts. GBS cultures, grown in BHI or M199, were centrifuged (4000 x g, $10 \mathrm{~min}, 4^{\circ} \mathrm{C}$ ) and washed three times in phosphate-buffered saline (PBS) $(150 \mathrm{mM}$ $\mathrm{NaCl}, 20 \mathrm{mM}$ phosphate buffer, $\mathrm{pH}$ 7.2). Bacteria (at the stationary growth phase) were then resuspended in $500 \mu 1$ of PBS supplemented with $0.1 \%$ Triton $\mathrm{X}-100$. An equivalent volume of glass beads $(0.3 \mathrm{~mm}$ in diameter) was then added to the suspensions, and cells were broken in a cell homogenizer (Braun Biotech International) by alternating 2-min shaking periods and 2-min cooling intervals ( 5 cycles). After removal of the glass beads, the suspensions were centrifuged at $4000 \mathrm{x} \mathrm{g}$ for $10 \mathrm{~min}$ at $4^{\circ} \mathrm{C}$, and the supernatants were used as cellular extract.

Cell-free culture supernatants. GBS cultures were centrifuged, and the supernatants were filtered through a $0.22-\mu \mathrm{m}$ membrane (Millipore). The cell-free culture supernatants were concentrated 100-fold using a 10,000 molecular weight cut-off Amicon micropartition system (Beverly, MA, USA) (15). Protein concentration was determined by the method described by Lowry et al (16), using BSA as standard.

Zymography. Peptidases were assayed and characterized by electrophoresis on $10 \%$ SDS-PAGE with $0.1 \%$ co-polymerized gelatin as substrate. Gels were loaded with $40 \mu \mathrm{g}$ of protein per slot. After electrophoresis, at a constant current of $120 \mathrm{~V}$ at $4{ }^{\circ} \mathrm{C}$, SDS was removed by incubation with 10 volumes of $1 \%$ Triton $\mathrm{X}-100$ for $1 \mathrm{~h}$ at room temperature under constant agitation. In order to promote the proteolysis, the gels were incubated for $48 \mathrm{~h}$ at $37^{\circ} \mathrm{C}$ in the following buffer systems: $10 \mathrm{mM}$ sodium citrate $(\mathrm{pH} 3.0), 50 \mathrm{mM}$ sodium phosphate buffer (pH 5.5) added to $2 \mathrm{mM}$ DTT and $20 \mathrm{mM}$ glycine$\mathrm{NaOH}(\mathrm{pH} \mathrm{10.0)}$ in the absence or presence of proteolytic inhibitors (10 mM PMSF, $10 \mathrm{mM}$ PHEN, $10 \mathrm{mM}$ EGTA, $10 \mathrm{mM}$ EDTA, $10 \mu \mathrm{M}$ pepstatin A and $10 \mu \mathrm{M}$ E-64). The gels were stained for $2 \mathrm{~h}$ with $0.2 \%$ Coomassie brilliant blue R-250 in methanol:acetic acid:water (50:10:40) and destained overnight in a solution containing methanol:acetic acid:water $(5: 10: 85)$, to intensify the digestion halos. The molecular masses of the peptidases were calculated by comparison with the mobility of low molecular mass standards. The gels were dried, scanned and digitally processed (15).

Cleavage of soluble protein components. Twenty microlitres of the concentrated culture supernatant from GBS strain 90356 was mixed with an equal volume of the following protein substrates: albumin, fibronectin, laminin, type IV collagen and fibrinogen. These proteins were diluted in $20 \mathrm{mM}$ glycine- $\mathrm{NaOH}$ ( $\mathrm{pH} 10.0$ ), to obtain a final concentration of $5 \mu \mathrm{g} / \mathrm{ml}$ in the reaction mixture. These preparations were incubated for $16 \mathrm{~h}$ at $37^{\circ} \mathrm{C}$, in the absence or presence of proteolytic inhibitors (10 mM PMSF, $10 \mathrm{mM}$ PHEN, $10 \mu \mathrm{M}$ pepstatin $\mathrm{A}$ and $10 \mu \mathrm{M}$ E-64). Reactions were terminated by freezing the samples, which were kept at $-20^{\circ} \mathrm{C}$ until their use in further analysis. The reaction mixtures were then added to $10 \mu 1$ SDS-PAGE sample buffer (125 mM Tris, $\mathrm{pH} 6.8 ; 4 \%$ SDS; $20 \%$ glycerol; $0.002 \%$ bromophenol blue) supplemented with $5 \%$ B-mercaptoethanol, followed by boiling at $100^{\circ} \mathrm{C}$ for $5 \mathrm{~min}$. The degradation protein profiles were analyzed on $10 \%$ SDS-PAGE. Electrophoresis was carried out at $100 \mathrm{~V}$ for $90 \mathrm{~min}$ at $4^{\circ} \mathrm{C}$, and the gels were stained with Coomassie brilliant blue R-250 in methanol:acetic acid:water (50:10:40) and destained in the same solvent solution. In order to control the possible degradation of the protein substrates, irrespective 
Table I. Characteristics of the GBS strains used in this study.

\begin{tabular}{lcccc}
\hline \multirow{2}{*}{ GBS strains (code) } & Serotype & Isolation & \multicolumn{2}{c}{ Antimicrobial susceptibility profile } \\
\hline 90356 & III & $\begin{array}{c}\text { Cerebrospinal fluid } \\
\text { (neonate) }\end{array}$ & $\begin{array}{c}\text { AMP, CEF, VAN, PEN, } \\
\text { ERI, IMI, NOR, CLI }\end{array}$ & Intermediate \\
80340 & III & Vagina (adult) & AMP, CEF, VAN, PEN, & TET \\
90186 & & ERI, IMI, NOR, CLI, SUL & TET \\
& V & Blood (adult) & AMP, CEF, VAN, PEN, & TET \\
\hline
\end{tabular}

AMP, ampicillin; CEF, ceftazidima; CLI, clindamycin; ERI, eritromicin; IMI, imipenem; NOR, norfloxacin; PEN, penicillin; SUL, sulfametoxazol/trimetoprim; TET, tetracyclin; VAN, vancomycin.

of GBS proteolytic enzymes, a second aliquot of the concentrated supernatant was heat-inactivated before the substrates were added. In addition, a control for each protein substrate was constructed by replacing concentrated supernatant with the same volume of glycine- $\mathrm{NaOH}$ buffer (15).

Effect of metallopeptidase inhibitors on GBS growth. The experiments were conducted in 10 x $100-\mathrm{mm}$ glass tubes containing $1 \mathrm{ml}$ of M199 medium. The inoculum consisted of $10 \%$ of a 6 -h culture of GBS (isolate 90356-CSF) containing $\sim 2.0 \times 10^{8}$ cells. EDTA and EGTA were dissolved in water at $100 \mathrm{mM}$, while PHEN was dissolved in DMSO at $100 \mathrm{mM}$. All drugs were filter-sterilized. The bacteria were incubated at $37^{\circ} \mathrm{C}$ for $1 \mathrm{~h}$, in the absence or presence of the metallopeptidase inhibitors at different concentrations (10, 1.0 and $0.1 \mathrm{mM}$ ). Cell growth was estimated by plating and counting the resulting colonies which appeared in the BAB plates containing 5\% sheep desfibrinated blood. Untreated and DMSO-treated GBS cultures were carried out in parallel as controls.

Endothelial cell culture. Human umbilical vein endothelial cells (HUVECs) were obtained by treatment of umbilical veins with a $0.1 \%$ collagenase IV solution as previously described (17). Primary cells were seeded into $25 \mathrm{~cm}^{2}$ bottles coated with porcine skin gelatin, and grown in M199 medium supplemented with $2 \mathrm{mM}$ glutamine, $2.5 \mu \mathrm{g} / \mathrm{ml}$ amphotericin $\mathrm{B}, 100 \mu \mathrm{g} / \mathrm{ml}$ penicillin, $100 \mu \mathrm{g} / \mathrm{ml}$ gentamycin, $0.13 \%$ sodium bicarbonate and $20 \%$ FCS. Cells were maintained at $37^{\circ} \mathrm{C}$ in a humidified $5 \% \mathrm{CO}_{2}$ atmosphere until they reached confluence. For experiments of interaction with bacteria, cells were maintained without antibiotics, unless otherwise stated.

Epithelial cell culture. A549 is a human type II alveolar epithelial-like lineage and is derived from lung carcinomatous tissue of a human patient, being widely used as a model of infection of respiratory pathogens. The cultures were maintained and grown to confluence in $25 \mathrm{~cm}^{2}$ culture flasks containing DMEM supplemented with $10 \% \mathrm{FCS}$, at $37^{\circ} \mathrm{C}$ in a $5 \% \mathrm{CO}_{2}$ atmosphere.
Bacterial binding and intracellular viability assays. Confluent cultures of HUVECs and A549 cells were allowed to interact with GBS $\left(5 \times 10^{7} \mathrm{CFU}\right)$ treated or not for $1 \mathrm{~h}$ with $10 \mathrm{mM}$ EDTA, $10 \mathrm{mM}$ EGTA and $0.1 \mathrm{mM}$ PHEN. For the bacterial binding assays, infected monolayers were rinsed three times with M199, and then lysed in a solution of $0.5 \mathrm{ml}$ of $25 \mathrm{mM}$ Tris, $5 \mathrm{mM}$ EDTA, $150 \mathrm{mM} \mathrm{NaCl}$ plus 1\% Igepal. The viability of total bacteria (intracellular plus surface adherent) was estimated by plating endothelial lysates and counting the resulting colonies which appeared in the BAB plates containing 5\% sheep desfibrinated blood. To measure bacterial internalization, the infected monolayers were incubated for $1 \mathrm{~h}$, rinsed three times with M199 medium, and incubated for an additional 2-h period in M199 containing bactericidal amounts of both gentamycin $(100 \mu \mathrm{g} / \mathrm{ml})$ and penicillin $\mathrm{G}(5 \mu \mathrm{g} / \mathrm{ml})$. The number of internalized bacteria was determined as outlined above. The adherence rates were determined as follows: [CFU of total cell-associated (intracellular viable plus surface adherent) GBS - CFU of intracellular GBS] (13).

Statistical analysis. All the experiments were repeated at least three times. All the conditions were performed in triplicate, and representative images of these experiments are shown. Statistical analysis of data was performed using the Student's t-test version EPI-INFO 6.04 (Database and Statistics Program for Public Health) computer software. $\mathrm{P} \leq 0.05$ was considered statistically significant.

\section{Results and Discussion}

Bacterial peptidases have diverse functions in pathogenesis. Peptidases can benefit the invading microbe by liberating nutrients from the host or by promoting disease through direct destruction of host tissues (18). Several peptidases activate host zymogens, such as plasminogen, kininogens, matrix metallopeptidases and proenzymes of the clotting system (19). Some of the peptidases inactivate host-defense proteins, such as immunoglobulins, components of the complement system and antimicrobial peptides (20), whereas others are required for intracellular survival in macrophages and for adherence to or uptake into host cells (21). 

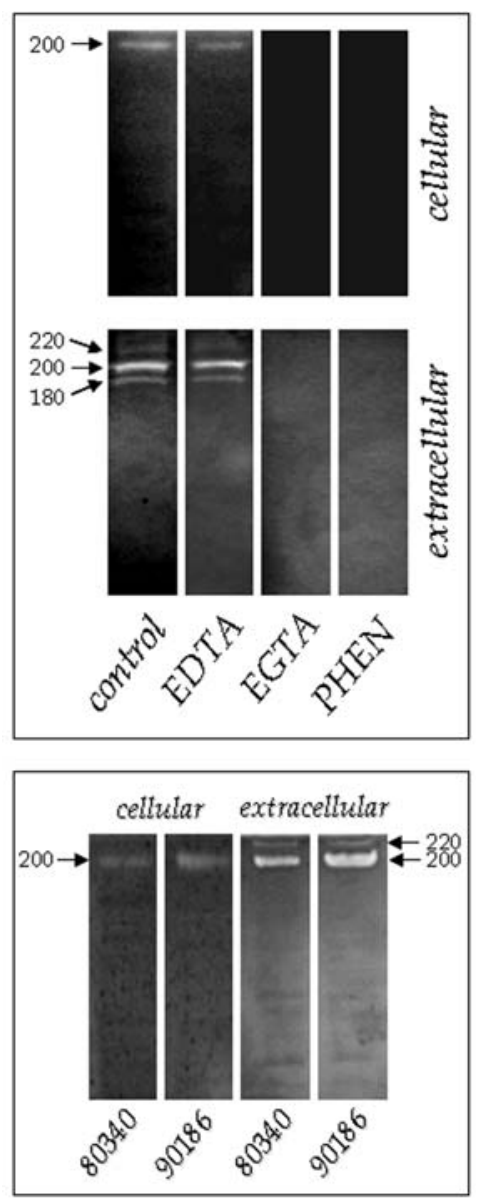

Figure 1. Proteolytic profiles detected in GBS cellular extract and in cellularfree culture supernatant obtained after culturing GBS 90356 strain (serotype III) in $\mathrm{M} 199$ medium for 16 to $18 \mathrm{~h}$ at $37^{\circ} \mathrm{C}$ (upper panel). The proteolytic activities were evidenced after zymographic analysis in gelatin SDS-PAGE, in which the gel strips were incubated for $48 \mathrm{~h}$ at $37^{\circ} \mathrm{C}$ in $20 \mathrm{mM}$ glycine$\mathrm{NaOH}, \mathrm{pH} 10.0$, in the absence (control) or in the presence of the following metallopeptidase inhibitors at $10 \mathrm{mM}$ : EDTA, EGTA or PHEN. The lower panel shows the cellular and the extracellular peptidases detected in two additional GBS clinical isolates: 80340 (serotype III) and 90186 (serotype V). The numbers indicate the apparent molecular masses of the peptidases expressed in kilodaltons.

GBS expresses a variety of extracellular products, which are implicated in virulence. Among these are the capsular polysaccharide, surface proteins and secreted proteins. In this study, we identified cell-associated and released proteolytic profiles generated by GBS strain 90356 isolated from cerebrospinal fluid. Since culture conditions could modulate the synthesis of bioactive molecules in microorganisms, we cultured GBS strains in two distinct media: BHI and M199. Our results showed that, in GBS cultures grown in M199, the extracellular proteolytic profile was composed of three gelatinolytic activities ranging from 180 to $220 \mathrm{kDa}$, whereas the cellular proteolytic profile was composed of a single peptidase of $200 \mathrm{kDa}$ (Fig. 1, upper panel). The same profile was identified in samples from GBS grown in BHI (data not shown). Thus, we chose GBS strain 90356 grown in M199 medium to carry out further experiments.

As is well known, some enzymes could be inactivated by SDS-PAGE. Thus, the three proteolytic enzymes observed on the zymograms might represent only a subset of the peptidases produced by GBS. The effect of $\mathrm{pH}$ on the peptidase activity was determined. Under the employed conditions, the proteolytic enzymes were active in an alkaline value of $\mathrm{pH} 10.0$ (Fig. 1, upper panel). Conversely, no proteolytic activity was observed in acidic conditions ( $\mathrm{pH} 3.0$ and 5.5) (data not shown). Proteolytic enzymes can be classified into four major groups as aspartic, cysteine, metallo- and serine peptidases, depending on the nature of the active site. Selective proteolytic inhibitors can be used to distinguish among these classes of peptidases. The peptidases synthesized by GBS strain 90356 had their activities completely inhibited by EGTA and PHEN, two powerful metallopeptidase inhibitors (Fig. 1, upper panel). On the other hand, serine (PMSF), cysteine (E-64) and aspartic (pepstatin A) proteolytic inhibitors did not alter the behavior of the peptidases (data not shown). Collectively, these results strongly suggest that the peptidases produced by GBS belong to the metallopeptidase class. Notably, an additional GBS strain (80340-serotype III) isolated from the vagina and another serotype of human importance (90186-serotype V) isolated from the blood (Table I) produced similar metallopeptidase profiles under the same growth conditions (Fig. 1, lower panel), suggesting that the production of metallo-type peptidases is a common feature of GBS species instead of being strain-specific. Thus, we elected GBS strain 90356 to perform the subsequent assays, since this clinical sample was used by our group in different ways in order to better characterize GBS physiology $(22,23)$.

Alkaline metallopeptidases produced by human pathogenic microorganisms show a wide variety of pathological actions. In local infections, metallopeptidases cause necrotic or hemorrhagic tissue damage through digestion of structural components of the ground substance, and also form edematous lesions through the generation of inflammatory mediators; whereas in systemic infections, they act as a synergistic virulence factor through disordered proteolysis of many plasma proteins $(24,25)$.

In order to obtain more information on the metallo-type peptidases produced by GBS, we tested their ability to hydrolyze a broad spectrum of protein substrates. In this context, we incubated the cell-free culture supernatant, rich in metallopeptidases, with important host serum proteins and extracellular matrix components. Our results showed that albumin, fibrinogen, laminin, fibronectin and type IV collagen were efficiently cleaved, generating a number of polypeptide bands of low molecular mass (Fig. 2, upper panel). In fact, the cleavage of key host components of the extracellular matrix by GBS may be a relevant factor in the process of bacterial dissemination and/or invasion. To determine the nature of the cleaving of these soluble proteins by the GBS peptidase, we incubated the culture supernatant in the presence of inhibitors of the four major peptidase classes. Addition of the metallopeptidase inhibitor PHEN completely inhibited these cleavages (data not shown). E-64, pepstatin A and PMSF did not alter the cleavage behavior of these soluble proteinaceous substrates (data not shown). Albumin hydrolysis in the presence or in the absence of proteolytic inhibitors is shown as a representative result of the previous set of experiments (Fig. 2, lower panel).

Previous studies show that metallopeptidases are involved in several metabolic pathways in different cellular types 

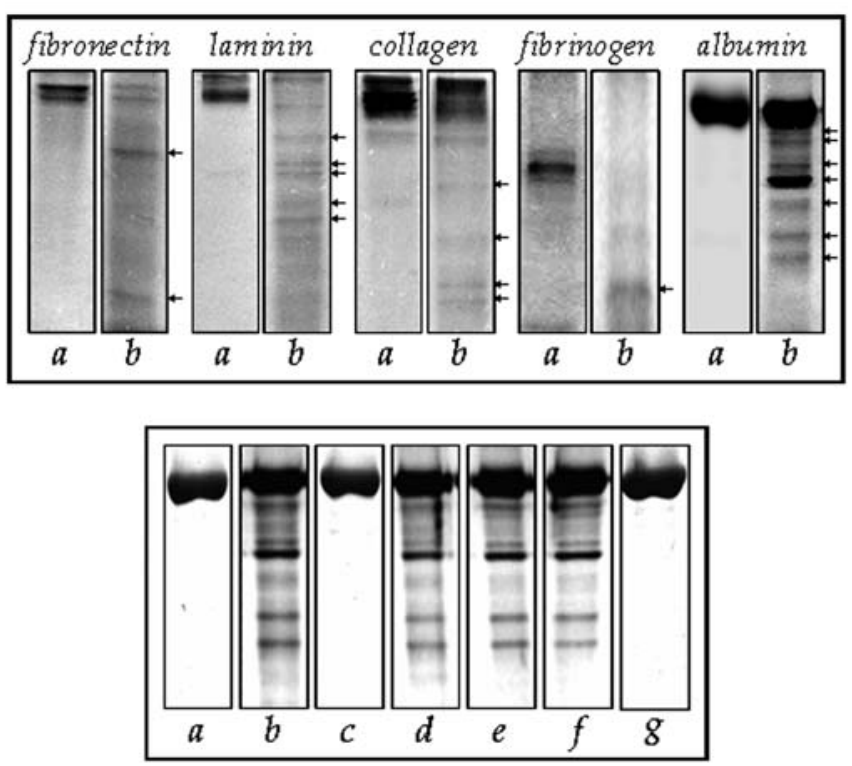

Figure 2. Cleavage of various soluble proteinaceous substrates by the extracellular peptidase activity of GBS (strain 90356). The degradation profile was analyzed on $10 \%$ SDS-PAGE, and gels were stained with Coomassie brilliant blue R-250. (Upper panel, b) Cell-free culture supernatant, rich in metallopeptidases, was incubated in the presence of human fibronectin, human placental laminin, type IV collagen, fibrinogen and human serum albumin for $16 \mathrm{~h}$ at $37^{\circ} \mathrm{C}$. Arrows indicate the fragmentation of the proteinaceous substrate after proteolysis. (Lower panel) The effect of different proteolytic inhibitors on the cleavage of soluble albumin. Culture supernatant was incubated for $16 \mathrm{~h}$ at $37^{\circ} \mathrm{C}$ in the absence (b) or in the presence of various proteolytic inhibitors: $10 \mathrm{mM}$ PHEN (c), $10 \mathrm{mM}$ PMSF (d), $10 \mu \mathrm{M}$ E-64 (e) and $10 \mu \mathrm{M}$ pepstatin A (f). Heat-inactivated culture supernatant (g). In both cases (upper and lower panels), a control (a) in which the proteinaceous substrate was supplemented only with glycine- $\mathrm{NaOH}$ buffer was used.

$(15,24)$. For this reason, we decided to investigate the possible involvement of metallopeptidases on the cellular development of GBS. Initially, three distinct metallopeptidase inhibitors (EDTA, EGTA and PHEN) were added to replicating GBS as a single dose (10 $\mathrm{mM})(15)$ and incubated at room temperature for $1 \mathrm{~h}$. Then, the bacterial suspensions were washed and plated on solid medium to measure the CFU. Our results showed that EDTA and EGTA, at the concentration used herein, did not affect GBS growth (Fig. 3). On the other hand, PHEN robustly inhibited GBS growth by $\sim 95 \%$ (Fig. 3). The drastic reduction of GBS development induced by PHEN was concentration dependent (Fig. 3). A comparable inhibition profile was observed when GBS strain 90186 was treated with the three metallopeptidase inhibitors (data not shown). DMSO, at the concentration used as a proteolytic inhibitor diluent, did not interfere with bacterial growth behavior (data not shown). PHEN and substituted derivatives, both in the metal-free state and as ligands co-ordinated to transition metals, disturb the functioning of a wide variety of biological systems (26). The in vitro antibacterial action of PHEN has been demonstrated on several species of bacteria, presenting bactericidal action towards many Gram-positive bacteria (27). Presumably, metallopeptidases assist GBS in deriving essential nutrients from human proteins, in maintaining GBS metabolic machinery and physiological processes such as cellular growth. However, PHEN could affect other metal-

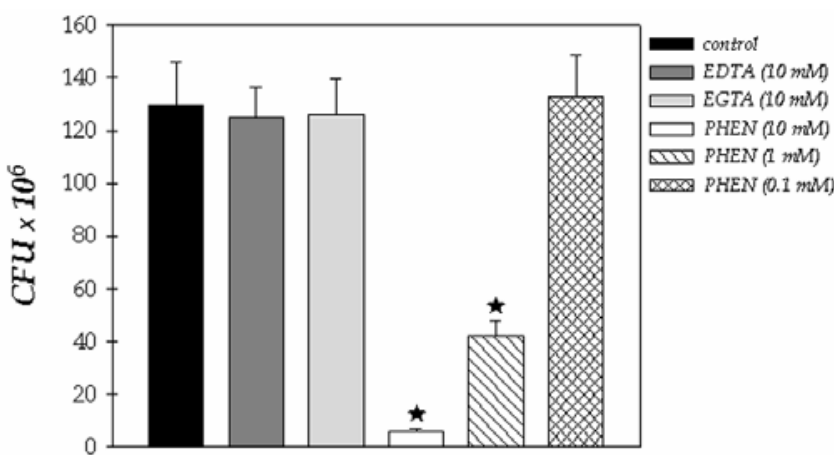

Figure 3. Effect of metallopeptidase inhibitors on the growth of GBS strain 90356. After growth in M199 medium, bacterial cells were pre-treated for $1 \mathrm{~h}$ in the absence (control) or in the presence of EDTA $(10 \mathrm{mM})$, EGTA $(10 \mathrm{mM})$ and PHEN (10,1 and $0.1 \mathrm{mM})$. Cells were then harvested, washed with PBS and inoculated in a fresh solid medium to measure the colonyforming units (CFU). The values represent the mean $\pm \mathrm{SD}$ of three independent experiments performed in triplicate. ${ }^{*} \mathrm{GBS}$ cells treated with proteolytic inhibitors having a growth rate significantly different from the controls $(\mathrm{P}<0.01$, Student's t-test $)$.
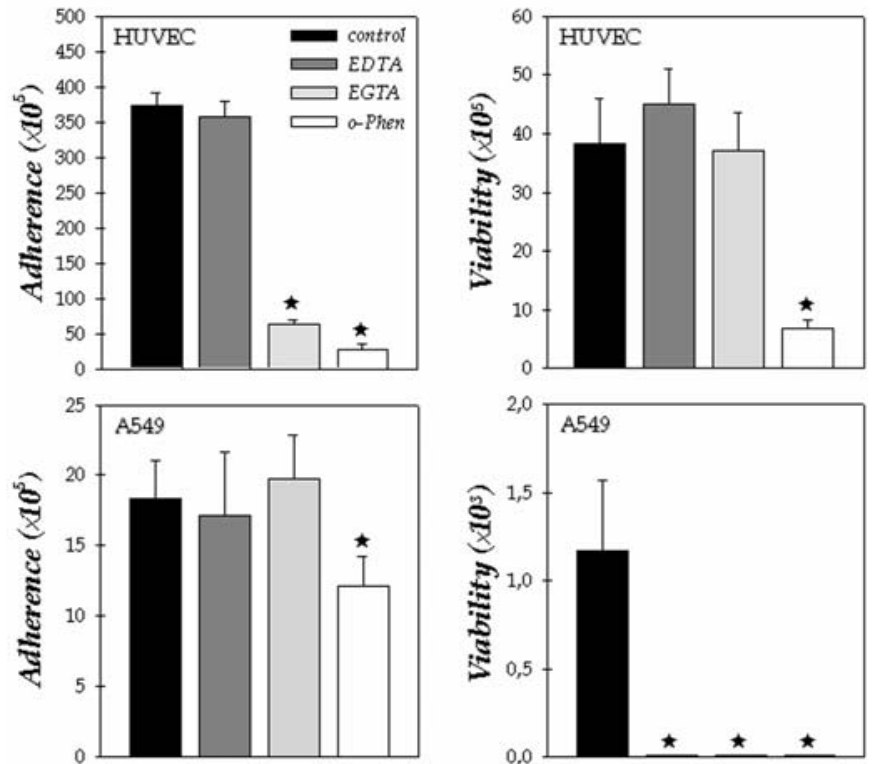

Figure 4. Interaction of GBS strain 90356 with two distinct cellular types: HUVECs (an endothelial lineage) and A549 (an epithelial lineage). Confluent cultures were allowed to interact with GBS previously treated or not for $1 \mathrm{~h}$ with $10 \mathrm{mM}$ EDTA, $10 \mathrm{mM}$ EGTA and $0.1 \mathrm{mM}$ PHEN. Analyses for adherence as well as for intracellular viability were performed as described in Materials and methods. Each value is the mean \pm SEM of four samples. *Systems treated with proteolytic inhibitors having an interaction rate significantly different from the controls $(\mathrm{P}<0.05$, Student's t-test).

dependent biological processes besides the activity of metallopeptidases, since this drug is a cell-permeable chelator.

Passage of GBS from the vaginal or intestinal mucosa to the amniotic fluid within the placenta or to the blood and meninges of a neonate is poorly defined. However, it is widely accepted that the organism must traverse several mucosal membrane barriers along the way. Although GBS does not replicate within respiratory epithelial cells, their ability to enter and survive in these cells and in macrophages (28) may 
be a mechanism by which they can cross mucosal membranes (1). Gibson et al (29) reported that GBS is able to invade lung endothelium in vitro and suggested that the ability of GBS to breach the endothelial barrier could provide a means for gaining access to vascular spaces or for entering interstitial spaces from the vascular compartment. Strains from invasive infections of infants are internalized by epithelial cells more effectively than from those from age-matched healthy controls (30), suggesting that invasion of epithelial cells significantly influences the pathogenesis of GBS. Winram et al (6) demonstrated that GBS can invade the chorionic epithelium and suggested that this could result in inflammatory damage to the amniotic membrane permitting streptococci to invade the amniotic fluid with subsequent infection of the fetus.

In our study, GBS strain 90356 adhered and invaded more efficiently to HUVECs than to the A549 epithelial cell line (Fig. 4). The difference in adherence between HUVECs and A549 cells reveals that GBS surface-bound proteins interact differently with cellular receptors. Using the HUVEC model, the adhesive property of strain 90356 was significantly inhibited by $\sim 83 \%(\mathrm{P}<0.001)$ and $93 \%(\mathrm{P}<0.001)$, respectively, after treatment with $10 \mathrm{mM}$ EGTA and $0.1 \mathrm{mM}$ PHEN (Fig. 4), while $10 \mathrm{mM}$ EDTA did not alter ( $\mathrm{P}>0.05)$ the adhesion between GBS and HUVECs (Fig. 4). Curiously, PHEN also strongly reduced (82\%) the intracellular viability of GBS in HUVECs (Fig. 4). A distinct pattern of interaction was observed between GBS and A549 cells (Fig. 4). In this context, PHEN slightly diminished the adhesion, whereas EDTA, EGTA and PHEN completely abolished the invasion process (Fig. 4). While GBS adheres to and invades HUVECs, the specific GBS factors that contribute to this process are only beginning to be elucidated. Proper anchoring of lipoteichoic acid on the GBS surface facilitates endothelial invasion, while the pore-forming hemolysin/cytolysin is cytolytic for human brain microvascular endothelial cells (hBMECs); each factor promotes blood-brain barrier penetration and lethality in a mouse model of hematogenous meningitis (31). A recent study also demonstrated that GBS fibrinogen-binding protein FbsA contributes to hBMEC adherence and invasion in vitro (32). Analysis of the NEM316 genome (a strain isolated from a case of fatal septicemia, serotype III) identified 71 secreted proteins, some of which are already known to contribute to pathogenesis (33). Most interestingly, the authors identified genes coding for yet uncharacterized putative secreted virulence factors such as two fibronectin-binding proteins (gbs1263, gbs0850) and a neuraminidase (gbs1919). The gbs1919 is highly similar (75\% similarity) to NanA of Streptococcus pneumoniae, an enzyme contributing to bacterial colonization and persistence in the nasopharynx and middle ear (34).

Our experiments do not eliminate the possibility that the identified metallopeptidases bind directly to endothelial cells via some unknown receptor, since PHEN inhibited the binding to endothelial and epithelial cells, but this activity would probably be overshadowed by the activity of another unidentified adhesin under these experimental conditions. Another explanation is that inactivation of peptidase activity protects another adhesin, which is normally cleaved in wildtype streptococci, or that conformational changes induced by the deletion exposed another adhesin. Interaction of these peptidases with either matrix fibronectin or an unidentified receptor could promote cytoskeletal changes that lead to ingestion of streptococci. Extracellular matrix proteins that serve as substrates for bacterial adherence include fibronectin, collagens, laminin, thrombospondin and integrins (35). These interactions may be particularly important for bacterial colonization of damaged tissues. GBS was previously shown to adhere to immobilized fibronectin, laminin and cytokeratin 8 $(11,36)$. The importance of these interactions for adherence/ invasion to endothelial/epithelial cells was not investigated. However, our results showed that GBS metallopeptidases degraded some of these extracellular matrix components. Further investigation is warranted in order to develop new strategies for treatment, not only of severe invasive GBS infections, but also of other bacterial diseases whose pathogenesis may involve endogenous and microbial peptidases. In this context, future studies are underway in our laboratory to determine the in vivo activities of the GBS peptidases and their mechanisms of regulation.

\section{Acknowledgements}

This work was supported by a grant from CNPq, CAPES, FAPERJ, FUJB and SR-2/UERJ.

\section{References}

1. Gibbs RS, Schrang S and Schuchat A: Perinatal infections due to group B streptococci. Obstet Gynecol 104: 1062-1076, 2004.

2. Blumberg HM, Stephes DS and Modansky M: Invasive group streptococcal disease: the emergency of serotype V. J Infect Dis 173: 365-373, 1996.

3. Teixeira CF, Azevedo NL, Carvalho TMU, Fuentes J and Nagao PE: Cytochemical study of Streptococcus agalactiae and macrophage interaction. Microsc Res Tech 54: 254-259, 2001.

4. Lalioui L, Pellegrini E, Dramsi S, Baptista M, Bourgeois N, Doucet-Populaire F, Rusniok C, Zouine M, Glaser P, Kunst F, Poyart C and Trieu-Cuot P: The SrtA sortase of Streptococcus agalactiae is required for cell wall anchoring of proteins containing the LPXTG motif, for adhesion to epithelial cells, and for colonization of the mouse intestine. Infect Immun 73: 3342-3350, 2005.

5. Jones S, Athan E and Viggers J: Prevention of recurrent fetal death in utero due to group B streptococcal chorioamnionitis. Aust J Obstet Gynaecol 44: 356-357, 2004.

6. Winram SB, Jonas M, Chi E and Rubens CE: Characterization of group B streptococcal invasion of human chorion and amnion epithelial cells in vitro. Infect Immun 66: 4932-4941, 1998.

7. Rubens CE, Raff HV, Jackson JC, Chi EY, Bielitzki JT and Hillier SL: Pathophysiology and histopathology of group B streptococcal sepsis in Macaca nemestrina primates induced after intraamniotic inoculation: evidence for bacterial cellular invasion. J Infect Dis 164: 320-330, 1991.

8. Doran KS and Nizet V: Molecular pathogenesis of neonatal group B streptococcal infection: no longer in its infancy. Mol Microbiol 54: 23-31, 2004.

9. Jackson RJ, Dao ML and Lim DV: Cell-associated collagenolytic activity by group B streptococci. Infect Immun 62: 5647-5651, 1994.

10. Lin B, Averett WF, Novak J, Chatham WW, Hollingshead SK, Coligan JE, Egan ML and Pritchard DG: Characterization of PepB, a group B streptococcal oligopeptidase. Infect Immun 64: 3401-3406, 1996.

11. Beckmann C, Waggoner JD, Harris TO, Tamura GS and Rubens CE: Identification of novel adhesins from group B streptococci by use of phage display reveals that $\mathrm{C} 5$ a peptidase mediates fibronectin binding. Infect Immun 70: 2869-2876, 2002.

12. Cheng QI, Stafslien D, Purushothaman SS and Cleary P: The group B streptococcal C5a peptidase is both a specific protease and an invasion. Infect Immun 70: 2408-2413, 2002. 
13. Santos GS, Miyazaki NHT, Mattos-Guaraldi AL and Nagao PE: The effects of interferon- $\gamma$ and transforming growth factor $-\beta$ on adherence and survival of group B Streptococcus type III strains in ECV304 cells. Int J Mol Med 11: 401-406, 2003.

14. Lancefield RD: Serological differentiation of human and other groups of hemolytic streptococci. J Exp Med 57: 571-595, 1933.

15. Palmeira VF, Kneipp LF, Alviano CS and Santos ALS: The major chromoblastomycosis fungal pathogen Fonsecaea pedroso $i$ extracellularly releases proteolytic enzymes whose expression is modulated by culture medium composition: implications on the fungal development and cleavage of key host structures. FEMS Immunol Med Microbiol 46: 21-29, 2006.

16. Lowry OH, Rosebrough NJ, Farr AL and Randall RJ: Protein measurement with the folin phenol reagent. J Biol Chem 193: 265-275, 1951.

17. Jaffe EA, Nacchman RL, Becker CG and Minick CR: Culture of human endothelial cells derived from umbilical cord veins. Identification by morphologic and immunologic criteria. J Clin Invest 52: 2745-2756, 1973 .

18. Lantz MS: Are bacterial proteases important virulence factors? J Periodontal Res 32: 126-132, 1997.

19. Lähteenmäki AK, Pentti K and Korhonen TK: Bacterial plasminogen activators and receptors. FEMS Microbiol Rev 25: 531-555, 2001.

20. Maeda $\mathrm{H}$ and Yamamoto T: Pathogenic mechanisms induced by microbial proteases in microbial infections. Biol Chem Hoppe Seyler 377: 217-226, 1996.

21. Gaillot O, Pellegrini E, Bregenholt S, Nair S and Berche P: The $\mathrm{ClpP}$ serine protease is essential for the intracellular parasitism and virulence of Listeria monocytogenes. Mol Microbiol 35: 1286-1294, 2000.

22. Lione VOF, Santos GS, Hirata R Jr, Mattos-Guaraldi AL and Nagao PE: Involvement of intercellular adhesion molecule-1 and beta 1 integrin in the internalization process to human endothelial cells of group B Streptococcus clinical isolates. Int J Mol Med 15: 153-157, 2005.

23. São José AS, Miyazaki NHT, Hirata R Jr, Mattos-Guaraldi AL and Nagao PE: Intracellular viability in non-polarized respiratory epithelial 16 HBE 140- cells by group B Streptococcus serotype III clinical isolates presenting $162-\mathrm{kb}$ and $183-\mathrm{kb}$ virulence markers. Int J Mol Med 17: 533-538, 2006.

24. Miyoshi S and Shinoda S: Microbial metalloproteases and pathogenesis. Microb Infect 2: 91-98, 2000.

25. Wu S, Dreyfus LA, Tzianabos AO, Hayashi C and Sears CL: Diversity of the metalloprotease toxin produced by enterotoxigenic Bacteroides fragilis. Infect Immun 70: 2463-2471, 2002 .
26. Butler HM, Hurse A, Thursky E and Shulman A: Bactericidal action of selected phenanthroline chelates and related compounds. Aust J Exp Biol Med Sci 47: 541-552, 1969.

27. Dwyer FP, Reid IK, Shulman A, Laycock GM and Dixson S: The biological actions of 1,10-phenanthroline and 2,2bipyridine hydrochlorides, quaternary salts and metal chelates and related compounds. Bacteriostatic action on selected grampositive, gram-negative and acid-fast bacteria. Aust J Exp Biol Med Sci 47: 203-218, 1969.

28. Valentin-Weigand P, Benkel P, Rohde M and Chhatwal GS: Entry and intracellular survival of group B streptococci in J774 macrophages. Infect Immun 64: 2467-2473, 1996.

29. Gibson RL, Soderland C, Henderson WR, Chi EY and Rubens CE: Group B streptococci (GBS) injure lung endothelium in vitro: GBS invasion and GBS-induced icosanoid production is greater with microvascular than with pulmonary artery cells. Infect Immun 63: 271-279, 1995.

30. Valentin-Weigand P and Chhatwal GS: Correlation of epithelial cell invasiveness of group B streptococci with clinical source of isolation. Microb Pathog 19: 83-91, 1995.

31. Maisey HC, Hensler M, Nizet V and Doran KS: Group B streptococcal pilus proteins contribute to adherence to and invasion of brain microvascular endothelial cells. J Bacteriol 189: 1464-1467, 2007.

32. Tenenbaum T, Bloier C, Adam R, Reinscheid DJ and Schroten H: Adherence to and invasion of human brain microvascular endothelial cells are promoted by fibrinogen-binding protein FbsA of Streptococcus agalactiae. Infect Immun 73: 4404-4409, 2005.

33. Glaser P, Rusniok C, Buchrieser C, Chevalier F, Frangeul L, Msadek T, Zouine M, Couvé E, Lalioui L, Poyart C, Trieu-Cuot P and Kunst F: Genome sequence of Streptococcus agalactiae, a pathogen causing invasive neonatal disease. Mol Microbiol 45: 1499-1513, 2002 .

34. Tong HH, Blue LE, James MA and De Maria TF: Evaluation of the virulence of a Streptococcus pneumoniae neuraminidasedeficient mutant in nasopharyngeal colonization and development of otitis media in the chinchilla model. Mol Microbiol 68: 921-924, 2000.

35. Joh D, Wann ER, Kreikemeyer B, Speziale P and Hook M: Role of fibronectin-binding MSCRAMMs in bacterial adherence and entry into mammalian cells. Matrix Biol 18: 211-223, 1999.

36. Tamura GS, Kuypers JM, Smith S, Raff H and Rubens CE: Adherence of group B streptococci to cultured epithelial cells: roles of environmental factors and bacterial surface components. Infect Immun 62: 2450-2458, 1994. 